\title{
Effects of Chewing Training on Orofacial and Cognitive Function in Healthy Individuals: A Systematic Review
}

\author{
Ricardo B. Viana * $\mathbb{D}^{\mathbb{D}}$, Wellington F. da Silva $\mathbb{D}$ and Claudio A.B. de Lira \\ Faculty of Physical Education and Dance, Federal University of Goiás, Goiânia 74690-900, Brazil; \\ wellingtonedfisica2@gmail.com (W.F.d.S.); andre.claudio@gmail.com (C.A.B.d.L.) \\ * Correspondence: vianaricardoborges@hotmail.com; Tel.: +55-62-3521-1141
}

Received: 6 February 2020; Accepted: 3 April 2020; Published: 6 April 2020

\begin{abstract}
Background: There is some evidence showing significant correlations between acute chewing gum and orofacial function, and between acute chewing gum and cognitive function; however, as far as we are aware, little is known about the chronic effects of chewing gum training on cognitive and orofacial functions in healthy adults. Objectives: To evaluate the chronic effects of chewing gum training on orofacial and cognitive functions in healthy adults. Method: Searches of the electronic databases PubMed, Scopus, BVS, CENTRAL, Scopus, and Google Scholar were conducted from inception to 14 January 2020. The inclusion criteria used were: clinical trial or randomized controlled trial lasting a minimum of four weeks, chewing gum intervention in at least one arm of the study, presence of a non-exercise control group, study population consisting of healthy adults, study outcomes consisting of orofacial function and/or cognitive function. Results: Starting from 5973 sources, a total of six articles met the inclusion criteria, and they were subjected to a systematic review. The main findings were that chewing gum training improved some variables related to orofacial function. No clear effect of chewing gum training on cognitive function was found. Conclusions: Chronic chewing gum training has an unclear positive effect on specific variables related to orofacial and cognitive function in healthy adults.
\end{abstract}

Keywords: gum chewing training; brain; tongue strength; cognition

\section{Introduction}

Chewing is a process generated by the central pattern generator in the brain stem [1], which involves rhythmic opening and closing of the jaw with coordinated movements of tongue, lips ad cheeks [2,3]. Moreover, the tongue helps in transferring the food to the right and left of the molars during chewing, and an expressive tongue pressure is necessary to form a bolus in the preparatory and oral stages of swallowing, and to transfer it to the pharynx [4]. Thus, for performing an oral function, it seems that the strength of the extraoral and intraoral muscles that support the mastication process is essential [5].

Also, chewing gum by itself might lead to positive behavioral changes in healthy individuals [6,7]. Indeed, a recent systematic review and meta-analysis reported that there is a modest link between chewing gum and sustained attention in healthy adults [8]. Furthermore, there is evidence suggesting that chewing gum appears to enhance driving performance during a sustained attention driving task in a driving simulator [9] and that chewing gum may be an easy way to increase student performance [10].

Hirano and Onozuka [11] showed in a systematic review study that acute chewing gum could influence levels of alertness and sustained attention in vigilance tasks; however, it seems that the chewing gum effect might be influenced by time-on-task effect and do not last so long, 15-20 [12] to 
$30 \mathrm{~min}$ [13]. Furthermore, this effect on memory performance appears most visible when information is presented in a non-verbal way [14].

Possible explanations for the effect of chewing gum on cognitive function may be related to a bilateral increases of neuronal activity within some areas of the brain (e.g., sensorimotor cortex, supplementary motor area, prefrontal cortex, insula, cerebellum, and thalamus) [15,16], as well as an increased release of insulin and an increased cerebral blood flow $[7,14,15,17]$. Shiba et al. [18] also found suppression of the parasympathetic nervous activity and/or enhancement of the sympathetic nervous activity for the heart of healthy adults after chewing gum. Thus, it seems that chewing gum might play a role in the modulation of autonomic nervous activity in healthy adults. Farella et al. [19] found a significant increase in heart rate (11 beats/min), systolic blood pressure $(14 \mathrm{mmHg})$, and masseter and anterior temporalis muscle activity when participants chewed a hard gum. Moreover, the increase in heart rate and systolic blood pressure remained significantly elevated after $10 \mathrm{~min}$ of recovery from exercise.

Wilkinson et al. [7] reported an improvement in simple reaction time measures after mimicked chewing when compared to gum-chewing and non-chewing control conditions. On the other hand, the authors did not find any significant change in choice reaction time and vigilance measures across the mimicked chewing, gum-chewing, and non-chewing control conditions. However, clinical studies are needed to improve existing protocols and reduce confounding effects (e.g., gum formulation, constituents, and intensity and frequency of chewing). Although previous studies found significant correlations between chewing gum and cognitive function [20] and there is a debate about the effects of chewing gum on cognitive functioning (e.g., learning and memory) [21] and orofacial function [22] in healthy adults, there are, so far as we are aware, no firm data about the cause-effect relationships between chronic chewing gum intervention and orofacial and cognitive function in humans. Furthermore, little is known about the improvements in cognitive and orofacial function after chronic chewing gum interventions in healthy adults compared to a non-exercise control group.

Therefore, taking together all this lack of information about the chronic effects of the chewing gum training on orofacial and cognitive function, our systematic review aims to evaluate the chronic effects of chewing training on orofacial and cognitive function in healthy adults compared to a non-exercise control group. We hypothesized that orofacial and cognitive function would improve after chewing training in healthy adults.

\section{Methodology}

The results of this systematic review are presented according to the Preferred Reporting Items for Systematic Reviews and Meta-Analysis (PRISMA) statement [23].

\subsection{Search Strategy}

English language searches of the electronic databases PubMed (Public/Publisher MEDLINE), Biblioteca Virtual em Saúde (BVS), Cochrane Central Register of Controlled Trials (CENTRAL), Scopus, and Google Scholar were conducted from inception to 14 January 2020 by two authors (R.V. and W.S). Furthermore, Portuguese language searches of the electronic databases Biblioteca Virtual em Saúde (BVS) and Google Scholar were conducted by two authors (R.V. and W.S.). There were no restrictions on the publication period. Articles were retrieved from electronic databases combining the following words: (i) (healthy adults OR adults OR healthy volunteers OR healthy individuals OR healthy participants) AND (ii) (chewing OR chewing training OR chewing exercise OR mastication OR mastication training OR mastication exercise OR eating OR eating training OR eating exercise) AND (iii) (orofacial function OR orofacial strength OR mouth function OR tongue function OR tongue strength OR lingual strength OR muscle strength OR brain OR brain function OR nervous system OR central nervous system OR CNS OR swallowing OR swallowing function OR cognition OR memory OR learning OR attention OR spatial OR executive functions). Initially, titles and abstracts of identified studies were checked for relevance by one author (R.V.). If the abstracts meet the criteria, two authors 
(R.V. and W.S.) independently reviewed the full text of potentially eligible studies. Any disagreement between the authors for inclusion was resolved by a third author (C.L.). Additional studies were identified via hand-searching and reviewing the reference lists of relevant papers. There was an agreement of $76.9 \%$ on the full text studies that should be included and excluded. Remaining studies were examined by a third author (C.L.).

All these steps were performed within three weeks. Figure 1 presents the flow of papers through the study selection process.

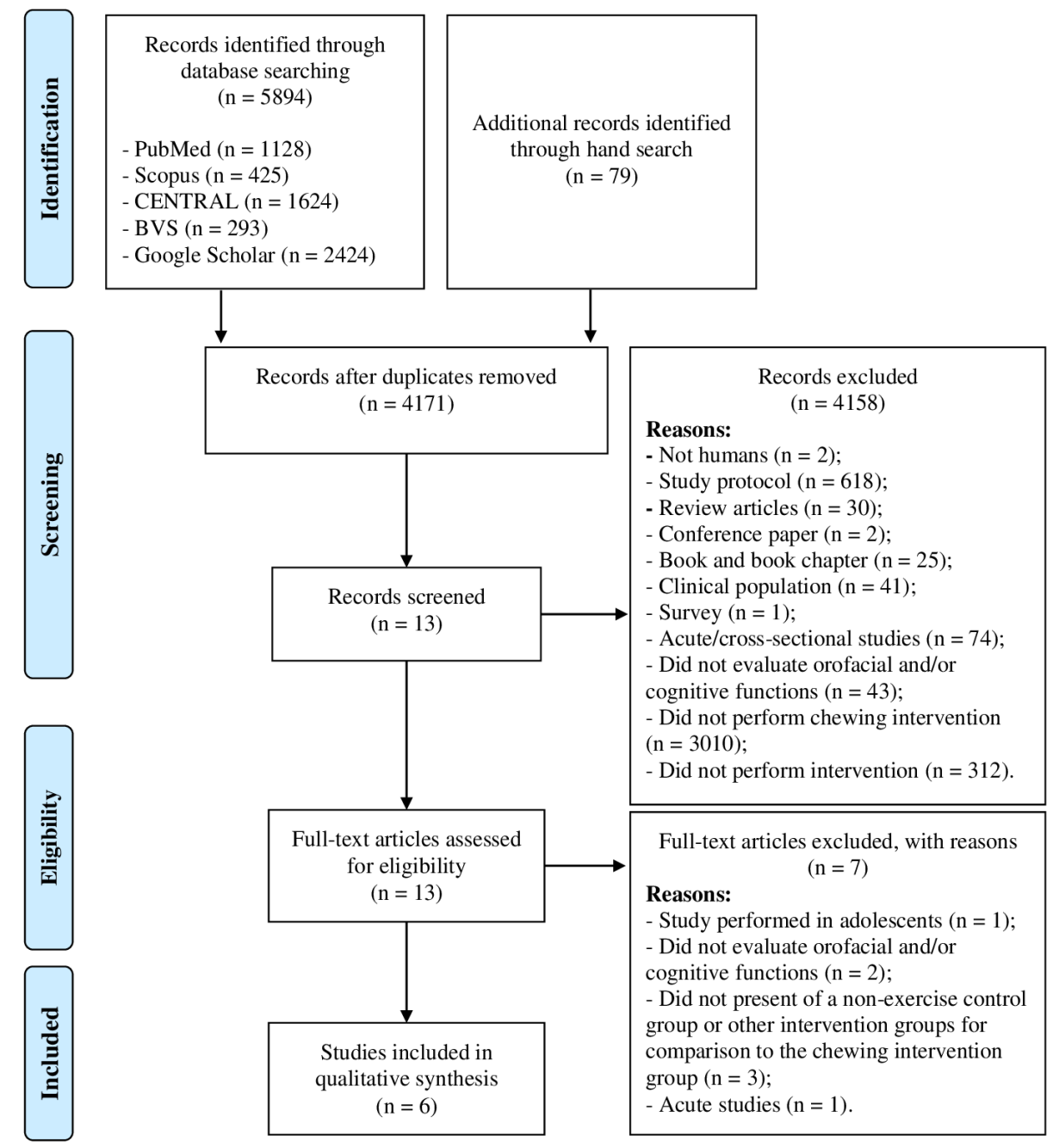

Figure 1. Diagram flow of outcomes of review.

\subsection{Inclusion and Exclusion Criteria}

The following criteria had to be met for inclusion: chronic clinical trial or randomized controlled trial lasting a minimum of four weeks, chewing gum intervention in at least one arm of the study, presence of a non-exercise control group, study population of healthy adults ( $\geq 18$ years), study outcomes of orofacial function and/or cognitive function. Textbooks, textbook sections, letters to the editor, conference abstracts, technical notes, guidelines, opinion articles, and reviews were excluded from this review. Only full-text studies published in English, Portuguese, or Spanish were included. There were no limitations for the year of publication.

\subsection{Data Extraction}

All data were extracted from the studies by two authors (R.V. and W.S.) using a pre-piloted form and included: (i) participant details (sample size, age (average, range, age groups), and sex); (ii) study 
methods (instrumental assessment and exercise intervention characteristics (gum characteristics, mouth side, pace of chewing, time of the day, intervention period, session duration and weekly frequency)); and (iii) study results.

\subsection{Study Quality and Risk of Bias Assessment}

Two authors (R.V. and W.S.) independently assessed the risk of bias of included studies using the Cochrane Collaboration's tool for assessing the risk of bias [24], including detection, attrition, reporting, and other sources of bias. Study quality was independently assessed by two authors (R.V. and W.S.) using the Physiotherapy Evidence Database (PEDro) scale [25], an 11-item scale that assesses methodological quality in randomized and non-randomized trials by rating them from 0 to 10 . A score of 6 represents the threshold score for studies of high quality. Specifically, studies scoring 9 or 10 on the PEDro scale were considered methodologically to be of "excellent" quality, scores ranging from 6 to 8 were considered to be of "good" quality, studies scoring 4 or 5 were of "fair" quality and studies scoring below 4 were felt to be of "poor" quality [26]. There was an agreement of 75.2\% and $85.1 \%$ on study quality and risk of bias assessment, respectively. Any discrepancies were resolved through discussion and when necessary by a third author (C.L.).

\subsection{Strategy for Data Synthesis}

A narrative synthesis of included studies was planned following guidelines from the Cochrane Collaboration [27]. Due to the inclusion of studies considering a range of independent variables (i.e., training, week frequency, etc.), they were grouped based upon these, and then their findings interpreted and synthesized concerning their designs and both strengths and weaknesses. The focus was given to the results of statistical tests reported by the authors of included studies (i.e., null hypothesis significance testing). From the interpretation of these strengths/limitations and knowledge of the wider literature/field, the synthesis was aimed to provide conclusions regarding the research question: does chewing training improve orofacial and cognitive functions in healthy adults?

\section{Results}

\subsection{Included Studies}

The search strategy retrieved 5973 records. After the deduplication examination, 1802 studies were excluded from the review process. Then, 4158 studies were excluded after the first screening and title and/or abstract analysis. Thirteen full-text copies of the remaining studies were obtained and subjected to further evaluation. After reading full-text copies, seven studies were excluded from this systematic review due to the following reasons: (i) one studied was performed in adolescents' individuals [10]; (ii) four studies did not evaluate orofacial or cognitive functions [28-31]; (iii) one study [32] did not present a non-exercise control group or other intervention groups for comparison to the chewing intervention group; and (iv) one study performed an acute chewing intervention [33]. Therefore, at the end of the process, six publications meeting the eligibility criteria were included for qualitative analysis [34-39], of which five studies evaluated orofacial function [34-38], and one study evaluated cognitive function [39]. The diagram flow of study selection and specific reasons for exclusion in the systematic review is presented in Figure 1.

\subsection{Participant Characteristics}

Overall, 140 participants were included in the systematic review. Fifty-three and 87 participants were included in the cognition function and orofacial function qualitative analysis, respectively. Three studies used the same participants [34-36]. One of five studies included in the orofacial function qualitative analysis examined men (Experiment 1) [37] exclusively, while the remaining studies $(n=4)$ assessed a mixed-sex sample [34-37]. The only study included in the qualitative cognition analysis examined a mixed-sex sample [39]. Participants' age of the orofacial included studies ranged from 20 
to 31 years [34-37]. The study included in the qualitative cognition analysis examined older adults [39]. Participants' characteristics are summarized in Table 1.

\subsection{Intervention Characteristics}

\subsubsection{Orofacial Function}

All studies applied a between-group study design, in which chewing gum interventions were compared with a non-chewing gum control group (no exercise) [34-38]. Although three studies measured different orofacial function outcomes, it seems that the author used the same study population [34-36]. Three studies used chewing gum intervention during four weeks [35-37] and one study for three months [38]. All studies applied chewing gum training sessions every day over the study intervention period [34-38]. The session time ranged from $15 \mathrm{~min}$ (three short sessions of five minutes over the same day) [38] to $60 \mathrm{~min}$ [34-36]. For all studies, participants performed the training daily. Four studies used hard chewing gum for the chewing gum intervention [34-36,38], while one study used a tooth brushing gum [37]. None study reported other gum characteristics (e.g., size [mm], flavor, and adherence [Newtons]) and the pace of chewing [34-38]. Only one study reported the mouth side (left side, right side, or both sides) used for chewing gum [38], in which participants were oriented to alternate chewing gum between ten times on the left and ten times on the right mouth side. Three studies reported that chewing gum sessions were performed mostly after meals [34-36], one study before or after the daily meals [37], and one did not report when chewing gum sessions occurred [38]. None of the studies reported compliance with chewing gum training. Chewing gum interventions are summarized in Table 2.

\subsubsection{Cognitive Function}

The only study that evaluated cognitive function applied between-group study design, in which chewing gum intervention (session time of $30 \mathrm{~min}$ [three times of $10 \mathrm{~min}$ ], every day over three months) was compared with a non-chewing gum control group (no exercise) [39]. Participants were required to chew mint-flavored sugar-free chewing gum. Participants recorded their chewing compliance through monthly calendars, and interim phone calls were made to all participants at day about one and two months after started the chewing gum training to enhance motivation and reinforce study retention. Chewing gum interventions are summarized in Table 2.

\subsection{Orofacial Function Assessment}

All studies measured different orofacial function variables (Table 3). One study [34] calculated the masticatory efficiency that was calculated using the weight of the almond before (A) and the weight of the pieces of the almond collected after the masticatory test (B), using the formula: Masticatory efficiency $=(A-B) / A \times 100$. One study measured the clinical dysfunction index, mean postural EMG activity of the anterior and posterior temporal and masseter muscles, mean EMG activity of the anterior and posterior temporal and masseter muscles during maximal clenching in the intercuspal position, and the mean relative loading of the anterior and posterior temporal and masseter muscles [35]. One study [36] measured maximal and mean bite force and endurance. The previously mentioned variables of orofacial function were measured two weeks before start the chewing intervention, on the first day, and after chewing training [34-36]; however, for this systematic review, we adopted the values measured on the first day of chewing training as the baseline values. Furthermore, one study [37] measured the anterior, posterior, and total occlusion contact force, as well anterior, posterior and total average occlusal contact pressure $\left(\mathrm{N} / \mathrm{mm}^{2}\right)$, and one study [38] measured the maximum tongue and cheek pressure $(\mathrm{kPa})$ using a tongue pressure measurement device (JMS Co., Hiroshima, Japan). 
Table 1. Study design and characteristics of the participants of the included studies.

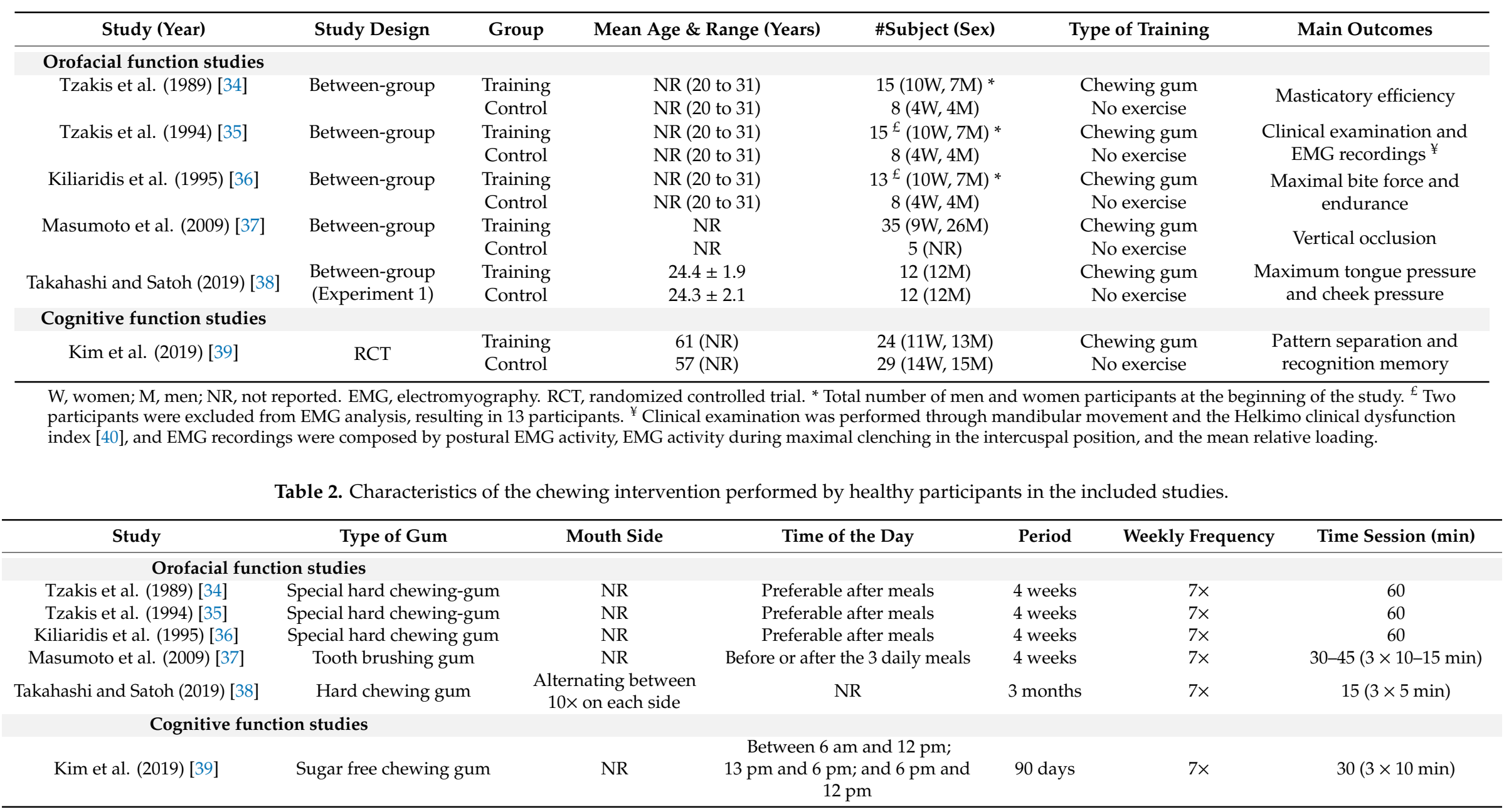


Table 3. Summary of the main results of the included studies.

\begin{tabular}{|c|c|c|c|c|c|c|c|c|c|}
\hline Study & Variable & Group & $\mathbf{n}$ & $\begin{array}{c}\text { Pre } \\
\text { Mean }\end{array}$ & Pre SD & $\begin{array}{l}\text { Post } \\
\text { Mean }\end{array}$ & Post SD & $\begin{array}{l}\text { Mean Change } \\
\text { (\%Change) }\end{array}$ & $p$-Value \\
\hline \multirow{9}{*}{$\begin{array}{l}\text { Tzakis et al. } \\
(1989)[34]\end{array}$} & Orofacial function studies & & & & & & & & \\
\hline & \multirow{2}{*}{ Masticatory efficiency (\%) } & Training & 15 & $71.0^{+}$ & $6.1^{+}$ & $73.0^{+}$ & $7.1^{+}$ & $2.1(2.9)^{£}$ & NS \\
\hline & & Control & 8 & $71.0^{+}$ & $8.3^{+}$ & $72.0^{+}$ & $8.3^{+}$ & $1.0(1.5)^{£}$ & NS \\
\hline & \multirow{2}{*}{ Mean postural EMG activity of the posterior temporal muscle $(\mu \mathrm{V})$} & Training & 13 & $10.2^{\dagger}$ & $10.5 \ddagger$ & $8.3^{+}$ & $7.5 \ddagger$ & $-1.9(-18.6)^{£}$ & NS \\
\hline & & Control & 8 & $7.9^{+}$ & $4.7 \ddagger$ & $8.8^{+}$ & $9.5 \ddagger$ & $0.9(11.4)^{£}$ & NS \\
\hline & \multirow{2}{*}{ Mean postural EMG activity of the anterior temporal muscle $(\mu \mathrm{V})$} & Training & 13 & $3.6^{+}$ & $2.6 \ddagger$ & $3.4^{+}$ & $2.5 \ddagger$ & $-0.2(-5.6)^{£}$ & NS \\
\hline & & Control & 8 & $4.2^{+}$ & $4.0 \ddagger$ & $3.3^{+}$ & $2.8^{\ddagger}$ & $-0.9(-21.4)^{£}$ & NS \\
\hline & \multirow{2}{*}{ Mean postural EMG activity of the masseter muscle $(\mu \mathrm{V})$} & Training & 13 & $1.8^{+}$ & $1.1 \ddagger$ & $1.6^{+}$ & $0.7 \ddagger$ & $-0.2(-11.1)^{£}$ & NS \\
\hline & & Control & 8 & $2.2^{\dagger}$ & $0.8^{\ddagger}$ & $2.9^{+}$ & $2.2 \ddagger$ & $0.7(31.8)^{£}$ & NS \\
\hline \multirow{12}{*}{$\begin{array}{l}\text { Tzakis et al. } \\
(1994)[35]\end{array}$} & \multirow{2}{*}{$\begin{array}{l}\text { Mean EMG activity of the posterior temporal muscle during maximal } \\
\text { clenching in the intercuspal position }(\mu \mathrm{V})\end{array}$} & Training & 13 & $192.9^{+}$ & $68.2 \ddagger$ & $251.6^{+}$ & $86.4 \ddagger$ & $58.7(30.4)^{£}$ & NS \\
\hline & & Control & 8 & $158.3^{+}$ & $51.7 \ddagger$ & $175.3^{+}$ & $76.7 \ddagger$ & $17.0(10.7)^{£}$ & NS \\
\hline & \multirow{2}{*}{$\begin{array}{c}\text { Mean EMG activity of the anterior temporal muscle during maximal } \\
\text { clenching in the intercuspal position }(\mu \mathrm{V})\end{array}$} & Training & 13 & $282.5^{+}$ & $141.4 \ddagger$ & $276.3^{+}$ & $148.0 \ddagger$ & $-6.2(-2.2)^{£}$ & NS \\
\hline & & Control & 8 & $349.3^{+}$ & $97.1 \ddagger$ & $332.1^{+}$ & $123.1 \ddagger$ & $-17.2(-4.9)^{£}$ & NS \\
\hline & \multirow{2}{*}{$\begin{array}{c}\text { Mean EMG activity of the masseter muscle during maximal clenching } \\
\text { in the intercuspal position }(\mu \mathrm{V})\end{array}$} & Training & 13 & $201.3^{+}$ & $186.4^{\ddagger}$ & $160.0^{+}$ & $130.1 \ddagger$ & $-41.3(-20.5)^{£}$ & NS \\
\hline & & Control & 8 & $185.5^{+}$ & $117.0 \ddagger$ & $144.2^{+}$ & $58.5 \ddagger$ & $-41.3(-22.3)^{£}$ & NS \\
\hline & \multirow{2}{*}{ The mean relative loading of the posterior temporal muscle ${ }^{¥}$} & Training & 13 & 7.8 & 11.8 & 3.9 & 3.8 & $-3.9(-50.0)^{£}$ & NS \\
\hline & & Control & 8 & 5.7 & 3.7 & 5.8 & 6.7 & $0.1(1.8)^{£}$ & NS \\
\hline & \multirow{2}{*}{ The mean relative loading of the ${ }^{¥}$ anterior temporal muscle } & Training & 13 & 2.1 & 2.7 & 1.6 & 1.1 & $0.5(-23.8)^{£}$ & NS \\
\hline & & Control & 8 & 1.3 & 1.2 & 1.2 & 1.2 & $-0.1(-7.7)^{£}$ & NS \\
\hline & \multirow{2}{*}{ The mean relative loading of the masseter muscle ${ }^{¥}$} & Training & 13 & 2.3 & 2.7 & 1.6 & 1.1 & $-0.7(-30.4)^{£}$ & NS \\
\hline & & Control & 8 & 1.9 & 1.5 & 2.0 & 1.0 & $0.1(5.3)^{£}$ & NS \\
\hline \multirow{6}{*}{$\begin{array}{l}\text { Kiliaridis et al. } \\
\text { (1995) [36] }\end{array}$} & \multirow{2}{*}{ Maximal bite force $(\mathrm{N})$} & Training & 13 & 573 & 173 & 673 & 162 & $100(17.5)^{£}$ & $<0.001$ \\
\hline & & Control & 8 & 676 & 192 & 710 & 191 & $34(5.0)^{£}$ & NS \\
\hline & \multirow{2}{*}{ Mean bite force for $10 \mathrm{~s}(\mathrm{~N})$} & Training & 13 & 448 & 158 & 518 & 124 & $70(15.6)^{£}$ & $<0.01$ \\
\hline & & Control & 8 & 573 & 201 & 561 & 198 & $-12(-2.1)^{£}$ & NR \\
\hline & \multirow{2}{*}{ Endurance time (seconds) } & Training & 13 & 40.0 & 19.0 & 38.4 & 15.7 & $-1.6(-4.0)^{£}$ & NS \\
\hline & & Control & 8 & 26.4 & 15.9 & 19.7 & 17.7 & $-6.7(-25.4)^{£}$ & NR \\
\hline \multirow{12}{*}{$\begin{array}{l}\text { Masumoto } \\
\text { et al. } \\
\text { (2009) [37] }\end{array}$} & \multirow{2}{*}{ Anterior occlusal contact force $(\mathrm{N})$} & Training & 35 & 218.1 & 29.5 & 266.5 & 39.4 & $48.4(25.0)$ & $<0.05$ \\
\hline & & Control & 5 & NR & NR & NR & NR & NR & NR \\
\hline & \multirow{2}{*}{ Posterior occlusal contact force $(\mathrm{N})$} & Training & 35 & 954.5 & 68.1 & 1101.8 & 64.7 & $147.3(18.5)$ & $<0.05$ \\
\hline & & Control & 5 & NR & NR & NR & NR & NR & NR \\
\hline & \multirow{2}{*}{ Total occlusal contact force $(\mathrm{N})$} & Training & 35 & 1172.5 & 83.6 & 1367.4 & 79.5 & $194.9(19.1)$ & $<0.05$ \\
\hline & & Control & 5 & NR & NR & NR & NR & NR & NS \\
\hline & \multirow{2}{*}{ Anterior average occlusal contact pressure $\left(\mathrm{N} / \mathrm{mm}^{2}\right)$} & Training & 35 & 37.9 & 5.7 & 34.9 & 5.4 & $-3.0(-7.9)^{£}$ & NS \\
\hline & & Control & 5 & NR & NR & NR & NR & NR & NR \\
\hline & \multirow{2}{*}{ Posterior average occlusal contact pressure $\left(\mathrm{N} / \mathrm{mm}^{2}\right)$} & Training & 35 & 36.3 & 6.1 & 34.6 & 4.2 & $-1.7(-4.7)^{£}$ & NS \\
\hline & & Control & 5 & NR & NR & NR & NR & NR & NR \\
\hline & \multirow{2}{*}{ Total average occlusal contact pressure $\left(\mathrm{N} / \mathrm{mm}^{2}\right)$} & Training & 35 & 36.4 & 5.8 & 34.6 & 4.1 & $-1.8(-5.0)^{£}$ & NS \\
\hline & & Control & 5 & NR & NR & NR & NR & NR & NR \\
\hline
\end{tabular}


Table 3. Cont.

\begin{tabular}{|c|c|c|c|c|c|c|c|c|c|}
\hline Study & Variable & Group & $\mathbf{n}$ & $\begin{array}{c}\text { Pre } \\
\text { Mean }\end{array}$ & Pre SD & $\begin{array}{l}\text { Post } \\
\text { Mean }\end{array}$ & Post SD & $\begin{array}{c}\text { Mean Change } \\
\text { (\%Change) }\end{array}$ & $p$-Value \\
\hline \multirow{4}{*}{$\begin{array}{l}\text { Takahashi and } \\
\text { Satoh } \\
\text { (2019) [38] }\end{array}$} & \multirow{2}{*}{ Maximum tongue pressure $(\mathrm{kPa})$} & Training & 12 & $40.1^{+}$ & $16.9^{\dagger}$ & $51.0^{+}$ & $15.5^{\dagger}$ & $10.9(27.1)^{£}$ & $<0.01$ \\
\hline & & Control & 12 & $40.9^{+}$ & $22.5^{\dagger}$ & $40.9^{\dagger}$ & $23.1^{\dagger}$ & $0.0(0.0)^{£}$ & NS \\
\hline & \multirow{2}{*}{ Cheek pressure $(\mathrm{kPa})$} & Training & 12 & $15.4^{+}$ & $7.0^{+}$ & $19.3^{+}$ & $8.3^{+}$ & $3.9(25.2)^{E}$ & $<0.01$ \\
\hline & & Control & 12 & $15.2^{+}$ & $5.2^{+}$ & $15.5^{\dagger}$ & $6.4^{+}$ & $0.3(2.1)^{£}$ & NS \\
\hline \multicolumn{10}{|c|}{ Cognitive function studies } \\
\hline \multirow{4}{*}{$\begin{array}{l}\text { Kim et al. } \\
\text { (2019) [39] }\end{array}$} & \multirow{2}{*}{ Lure discrimination index } & Training & 23 & 0.27 & NR & 0.21 & NR & $-0.06(-22.2)^{£}$ & NS \\
\hline & & Control & 28 & 0.25 & NR & 0.24 & NR & $-0.01(-4.0)^{E}$ & NS \\
\hline & \multirow{2}{*}{ Recognition score } & Training & 23 & 0.70 & NR & 0.81 & NR & $0.11(17.7)^{£}$ & $<0.05$ \\
\hline & & Control & 28 & 0.82 & NR & 0.79 & NR & $-0.03(-3.7)^{£}$ & NS \\
\hline
\end{tabular}

SD, standard deviation; EMG, electromyography; NR, not reported; NS, non-significant. ${ }^{£}$ Percentage change was estimated dividing post mean value by pre mean value and then multiplying by $100 .{ }^{¥}$ Mean relative loading was calculated as the percentage of ratio between postural and maximal clenching EMG activity. ${ }^{\dagger}$ Extrapolated from graph through an online software (WebPlotDigitizer). $¥$ Standard error of the mean (SEM) values were extrapolated from graph and SEM was converted to SD using SD $=$ SEM $\times$ Sqrt ${ }^{\circ}$. 


\subsection{Cognitive Function Assessment}

The only study which measured cognitive function [39] applied a mnemonic similarity task, which quantitatively measures pattern separation and recognition memory performance in humans. This cognition test consists of two separate phases (encoding task and memory task) using a series of color photographs of everyday objects on a white background. The authors used the lure discrimination index and recognition score, as suggested by Stark et al. [6], to evaluate the change in cognition after the chewing intervention period. Briefly, the authors reported that the lure discrimination index and the recognition score provide information about the pattern separation performance and recognition memory performance, respectively. The first one is represented by the difference between the rates of 'similar' responses given to lure items minus 'similar' responses given to foils, while the second one is represented by the rate of 'old' responses given to repeat items minus 'old' responses given to foils.

\subsection{Main Results}

\subsubsection{Orofacial Function}

Tzakis et al. [34] found no significant change in masticatory performance either in the chewing group or control group after the intervention study period (four weeks). Tzakis et al. [35] found that the chewing intervention group had a significant reduction $(p<0.01)$ in the clinical dysfunction index during the training period, although it was back at the baseline level at the end chewing training intervention. The authors did not report the statistical results for the control group (baseline $\times$ post-intervention period). Furthermore, they did not find any within-group changes in the EMG activity and mean relative loading of the measured muscles (anterior and posterior temporal and masseter either in the postural position or during maximal clenching) either in the chewing intervention group or control group. Kiliaridis et al. [36] found a significant increase in the maximal bite force $(+17.5 \%)$ and mean bite force for $10 \mathrm{~s}(+15.6 \%)$ in the experimental group after the training period but not in the control group. Furthermore, the authors found no significant increase in the endurance time after the training period, either for the intervention group or the control group. Masumoto et al. [37] found a significant increase in the anterior $(25.0 \%)$, posterior $(18.5 \%)$ and total occlusal contact force $(19.1 \%)$, and a significant reduction in the anterior average $(-7.9 \%)$, posterior average $(-4.7 \%)$ and total average occlusal contact pressure $\left(\mathrm{N} / \mathrm{mm}^{2}\right)(-5.0 \%)$ only for the chewing intervention group. Four [34-37] of the five studies which measured some variable related to orofacial function did not perform between-group analysis to identify possible differences between the chewing intervention group versus control group for the investigated variables. Only one study [38] performed a between-groups analysis. The authors found a significant increase in the maximum tongue pressure $(27.1 \%)$ and cheek pressure $(25.2 \%)$ in the experimental group when compared to the control group. Table 3 shows a summary of the orofacial function results reported in the included studies.

\subsubsection{Cognitive Function}

The only study which evaluated cognitive function after chewing intervention [39] found a significant increase in the recognition score but not lure discrimination index in the chewing intervention group when compared to a control group. Table 3 shows a summary of the cognitive function results. 


\subsection{Study Quality and Risk of Bias}

Three $[34,35,38]$ of the studies which evaluated orofacial function presented "fair" quality (score: 4-5/10), and the other two studies [36,37] presented a "poor" quality (score: 3/10). The study which evaluated cognitive function [39] presented a "fair" quality (score: 5/10). All included studies satisfied criteria 8 (measures of at least one key outcome were obtained from more than $85 \%$ of the subjects initially allocated to groups), 9 (all subjects for whom outcome measures were available received the treatment or control condition as allocated or, where this was not the case, data for at least one key outcome were analyzed by "intention to treat"), and 11 (the study provides both point measures and measures of variability for at least one key outcome). Criteria 3 (allocation concealed), 5 (blinding of all subjects), and 6 (blinding of all therapists who administered the therapy) were not satisfied by any of the included studies. Only one study [35] satisfied criterion 7 (blinding of all assessors who measured at least one key outcome). Table 4 shows additional information about study quality assessment.

Overall, the risk of bias assessment through the Cochrane 'risk of bias' tool shows that the included studies in this review presented an unclear risk of bias. Only one study [39] clearly stated that randomization was performed, although there was no information about the allocation concealment. None of the studies blinded the participants and personnel, and only one study [35] blinded the outcome assessment. Thus, it potentially might limit the reviews' conclusions given the limited available data on the topic. 
Table 4. Description of studies quality based on Physiotherapy Evidence Database Scale (PEDro).

\begin{tabular}{|c|c|c|c|c|c|c|c|c|c|c|c|c|}
\hline Study & $\begin{array}{l}\text { Eligibility } \\
\text { Criteria }\end{array}$ & $\begin{array}{l}\text { Random } \\
\text { Allocation }\end{array}$ & $\begin{array}{l}\text { Concealed } \\
\text { Allocation }\end{array}$ & $\begin{array}{c}\text { Baseline } \\
\text { Comparability }\end{array}$ & $\begin{array}{l}\text { Blind } \\
\text { Subjects }\end{array}$ & $\begin{array}{l}\text { Blind } \\
\text { Therapists }\end{array}$ & $\begin{array}{l}\text { Blind } \\
\text { Assessors }\end{array}$ & $\begin{array}{l}\text { Adequate } \\
\text { Follow-up }\end{array}$ & $\begin{array}{c}\text { Intention-to-Treat } \\
\text { Analysis }\end{array}$ & $\begin{array}{l}\text { Between-Group } \\
\text { Comparisons }\end{array}$ & $\begin{array}{l}\text { Point Estimates } \\
\text { and Variability }\end{array}$ & $\begin{array}{l}\text { PEDro } \\
\text { Score }\end{array}$ \\
\hline \multicolumn{13}{|l|}{ Orofacial function studies } \\
\hline Tzakis et al. (1994) [34] & Y & $\mathrm{N}$ & $\mathrm{N}$ & $\mathrm{Y}$ & $\mathrm{N}$ & $\mathrm{N}$ & $\mathrm{N}$ & Y & $\mathrm{Y}$ & $\mathrm{N}$ & $\mathrm{Y}$ & 4 \\
\hline Tzakis et al. (1994) [35] & Y & $\mathrm{N}$ & $\mathrm{N}$ & $\mathrm{Y}$ & $\mathrm{N}$ & $\mathrm{N}$ & $\mathrm{Y}$ & Y & $\mathrm{Y}$ & $\mathrm{N}$ & $\mathrm{Y}$ & 5 \\
\hline Kiliaridis et al. (1995) [36] & Y & $\mathrm{N}$ & $\mathrm{N}$ & $\mathrm{N}$ & $\mathrm{N}$ & $\mathrm{N}$ & $\mathrm{N}$ & Y & $\mathrm{Y}$ & $\mathrm{N}$ & $\mathrm{Y}$ & 3 \\
\hline Masumoto et al. (2009) [37] & $\mathrm{Y}$ & $\mathrm{N}$ & $\mathrm{N}$ & $\mathrm{N}$ & $\mathrm{N}$ & $\mathrm{N}$ & $\mathrm{N}$ & Y & $\mathrm{Y}$ & $\mathrm{N}$ & Y & 3 \\
\hline $\begin{array}{l}\text { Takahashi and Satoh } \\
\text { (2019) [38] }\end{array}$ & Y & $\mathrm{N}$ & $\mathrm{N}$ & Y & $\mathrm{N}$ & $\mathrm{N}$ & $\mathrm{N}$ & Y & Y & Y & Y & 5 \\
\hline \multicolumn{13}{|l|}{ Cognitive function studies } \\
\hline Kim et al. (2019) [39] & $\mathrm{Y}$ & $\mathrm{Y}$ & $\mathrm{N}$ & $\mathrm{N}$ & $\mathrm{N}$ & $\mathrm{N}$ & $\mathrm{N}$ & $\mathrm{Y}$ & Y & $\mathrm{Y}$ & Y & 5 \\
\hline
\end{tabular}

$\mathrm{Y}$, yes; N, no. Eligibility criteria item does not contribute to total score. 


\section{Discussion}

This study reviewed systematically the effects of chronic chewing gum training on orofacial and cognitive function in healthy adults compared to a non-exercise control group. Our main findings were that chewing gum training improved some variables related to orofacial function (e.g., maximum tongue pressure, cheek pressure, occlusal contact force, and maximal bite force), whereas some studies have not found positive results on other variables (endurance time during a maximal bite force test, masticatory efficiency and EMG activity of masticatory muscles [temporal and masseter]). Furthermore, we found an uncertain effect of chewing gum training on cognitive function, since the two variables (lure discrimination index and recognition score) investigated by the only study which evaluated cognitive function had different responses.

\subsection{Orofacial Function}

The chewing gum training improved maximum tongue pressure, cheek pressure, occlusal contact force, and maximal bite force, but not masticatory efficiency and EMG activity of temporal and masseter muscles. Therefore, we present below information about all strengths and concerns about the included studies.

Tzakis et al. [34] found no significant improvement in masticatory efficiency after four weeks of chewing gum training. One of the possible explanations for this result may be related to the "ceiling effect," as the participants in the Tzakis et al. [34] study had an optimal masticatory efficiency at baseline. In another study from Tzakis et al. group [35], no significant improvements in EMG activity of three masticatory muscles (anterior and posterior temporal and masseter) after four weeks of chewing gum training were found. Moreover, the chewing gum training, after seven days of 60 min of daily chewing gum training, elicited a considerable increase in the symptoms of craniomandibular disorders-like effects on masticatory muscles. The authors reported that it might be related to the increase and intense use of the masticatory system with no rest period.

One year later, the same research group published another study (Kiliaridis et al. [36]) reporting a significant increase in maximal bite force (an indicator of the functional state of the masticatory system [41]), but not in fatigue resistance of the masticatory muscles in healthy adults. However, it is important to highlight that in the control group of the study by Kiliaridis et al., the baseline values of the maximal bite force were higher than those in the chewing gum training group, which might have influenced the control group within-group analysis. The authors justified this baseline group differences potentially due to the different sex distribution between the groups (more women in the chewing training group). Because of that, no between-group analysis was performed, and therefore, we do not know if the increases in maximal bite force after four weeks of daily chewing training are different from those in the non-chewing gum training control group. Furthermore, many factors can influence the measurement of maximal bite force, such as the presence of pain and temporomandibular disorders, gender, age, craniofacial morphology, occlusal factors, recording devices, and measurement techniques [41]. It is noteworthy that Tzakis et al. [34], Tzakis et al. [35], and Kiliaridis et al. [36] studies used the same study population, and for this reason, these studies share the same limitations.

Masumoto et al. [37] found a significant increase in the occlusal contact force but not average occlusal contact force (N/mm²) after 30-45 min of daily chewing gum training split in three different moments of the day (before or after the meals). However, the authors did not perform any between-group analysis, which precludes the link of the chewing gum training improvements in occlusal contact force when compared to a non-chewing gum control group. Conversely, Takahashi and Satoh [38] performed a study comparing the changes in maximum tongue pressure and cheek pressure between a chewing gum group (15 min [three times of five minutes per day] of daily chewing gum) and a non-chewing gum control group. They found a significant interaction between the group (experimental versus control group) and time factor (baseline versus post-intervention period) for maximum tongue pressure and cheek pressure. In simple words, Takahashi and Satoh [38] found that the chewing gum group had a significant improvement in maximum tongue pressure (27.1\%) and 
cheek pressure (25.2\%) when compared to a non-chewing exercise control group. Thus, the authors have countered for the random error influence [42].

\subsection{Cognitive Function}

The only study which measured cognitive function [39] evaluated the changes in cognition after 90 days of daily chewing gum training (30 $\mathrm{min}$ per day [three times of $10 \mathrm{~min}$ ]), found different results for the two cognitive function variables investigated (no change in the lure discrimination index and increase in the recognition score). This result might be related to the fact that the baseline values of the variable recognition score were significantly different between the chewing gum and control groups. Therefore, the "success" of the chewing gum intervention needs to be carefully interpreted.

\subsection{Strength and Limitations of the Included Studies}

Strengths of this review include the comprehensive search strategy of five databases, review of reference lists of relevant reviews and reference lists of all included trials, and the risk of bias through the Cochrane 'risk of bias' tool and systematic appraisal of study quality through the PEDro scale. On the other hand, this systematic review has some limitations that should be mentioned. Firstly, there is a small number of included studies that evaluated the chronic effects of chewing gum training intervention on orofacial function $(n=5)$, and especially on cognitive function $(n=1)$. Secondly, the included studies present a "fair" quality and an unclear risk of bias (Figure 2). It is noteworthy that none of the studies which investigated changes in orofacial function randomized the participants for the experimental (chewing gum) or control group (non-chewing gum). Thirdly, each study which investigated changes in orofacial function evaluated a different variable (masticatory efficiency [34]; EMG activity of masticatory muscles [35]; maximal bite force, mean bite force for $10 \mathrm{~s}$, and endurance time [36]; occlusal contact force and average occlusal contact pressure $\left(\mathrm{N} / \mathrm{mm}^{2}\right)$ [37]; and maximum tongue pressure and cheek pressure [38]). Thus, these studies presented a higher heterogeneity regarding the orofacial function variable. Fourthly, three [34-36] of the five studies which measured orofacial function used the same study population, and therefore, they share the same study limitations, such as the lack of a between-group analysis and a disproportional number of men and women in the chewing gum and control groups. Fifthly, although most of the included studies reported the type of gum (special hard chewing-gum), most of them did not provide any information about the gum size, flavor, adherence, mouth side used to chew, and pace of chewing. Therefore, these limitations potentially might limit clear conclusions given the limited available data on the topic. Furthermore, clinicians must be careful when interpreting these results and applying them to their practice.

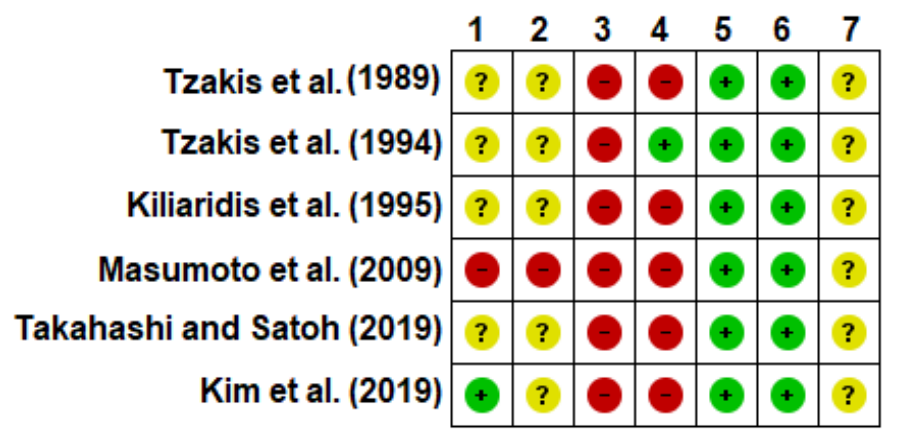

Figure 2. Risk of bias summary. 1. Random sequence generation (selection bias); 2. Allocation concealment (selection bias); 3. Blinding of participants and personnel (performance bias); 4. Blinding of outcome assessment (detection bias); 5. Incomplete outcome data (attrition bias); 6. Selective reporting (reporting bias); 7. Other bias. Note: The judgement for each entry involved assessing the risk of bias as 'low risk' (green), as 'high risk' (red), or as 'unclear risk' (yellow), with the last category indicating either lack of information or uncertainty over the potential for bias [24]. 
Given the limitations reported above, although chewing gum might be an easy oral intervention method, further studies are needed and must improve their methodological quality, method of assessment of orofacial and cognitive function to provide more information about the effects of chewing gum training interventions in healthy individuals. Finally, different chewing gum training intervention is needed to clarify if there is some training volume, training supervision by a therapist, time and pace of chewing, as well as other key factors.

\section{Conclusions}

Chronic chewing gum training intervention has an unclear positive effect on cognitive and orofacial function in healthy adults when compared to a non-exercise control group. Furthermore, as most of the included studies did not randomize the participants to the control or chewing training group and did not perform between-group analysis, it is necessary to exercise caution when interpreting the present findings.

Author Contributions: R.B.V. and W.F.d.S. carried out the screenings and reviews. R.B.V. and W.F.d.S. carried out the analysis of the articles. R.B.V. and W.F.d.S. drafted and revised the manuscript. R.B.V., W.F.d.S. and C.A.B.d.L. revised the manuscript. All authors have read and agreed to the published version of the manuscript.

Funding: This research received no external funding.

Acknowledgments: None.

Conflicts of Interest: The authors declare no conflict of interest.

\section{References}

1. Lund, J.P.; Kolta, A. Generation of the central masticatory pattern and its modification by sensory feedback. Dysphagia 2006, 21, 167-174. [CrossRef] [PubMed]

2. Saitoh, I.; Hayasaki, H.; Nakata, S.; Iwase, Y.; Nakata, M. Characteristics of the gum chewing occlusal phase in children with primary dentition. J. Oral Rehabil. 2004, 31, 406-411. [CrossRef] [PubMed]

3. Prinz, J.F.; Lucas, P.W. "The first bite of the cherry" intra-oral manipulation prior to the first bite in humans. J. Oral Rehabil. 2001, 28, 614-617. [CrossRef] [PubMed]

4. Nicosia, M.A.; Hind, J.A.; Roecker, E.B.; Carnes, M.; Doyle, J.; Dengel, G.A.; Robbins, J. Age effects on the temporal evolution of isometric and swallowing pressure. J. Gerontol. Ser. A Biol. Sci. Med. Sci. 2000, 55, M634-M640. [CrossRef] [PubMed]

5. Ibrahim, F.; Arifin, N.; Rahim, Z.H.A. Effect of Orofacial Myofunctional Exercise Using an Oral Rehabilitation Tool on Labial Closure Strength, Tongue Elevation Strength and Skin Elasticity. J. Phys. Ther. Sci. 2013, 25, 11-14. [CrossRef]

6. Stark, S.M.; Stevenson, R.; Wu, C.; Rutledge, S.; Stark, C.E.L. Stability of age-related deficits in the mnemonic similarity task across task variations. Behav. Neurosci. 2015, 129, 257-268. [CrossRef]

7. Wilkinson, L.; Scholey, A.; Wesnes, K. Chewing gum selectively improves aspects of memory in healthy volunteers. Appetite 2002, 38, 235-236. [CrossRef]

8. Miquel, S.; Haddou, M.B.; Day, J.E.L. A systematic review and meta-analysis of the effects of mastication on sustained attention in healthy adults. Physiol. Behav. 2019, 202, 101-115. [CrossRef]

9. Yoo, I.; Kim, E.-J.; Lee, J.-H. Effects of chewing gum on driving performance as evaluated by the STISIM driving simulator. J. Phys. Ther. Sci. 2015, 27, 1823-1825. [CrossRef]

10. Johnston, C.A.; Tyler, C.; Stansberry, S.A.; Moreno, J.P; Foreyt, J.P. Brief report: Gum chewing affects standardized math scores in adolescents. J. Adolesc. 2012, 35, 455-459. [CrossRef]

11. Hirano, Y.; Onozuka, M. Chewing and Attention: A Positive Effect on Sustained Attention. Biomed Res. Int. 2015, 2015, 1-6. [CrossRef] [PubMed]

12. Onyper, S.V.; Carr, T.L.; Farrar, J.S.; Floyd, B.R. Cognitive advantages of chewing gum. Now you see them, now you don't. Appetite 2011, 57, 321-328. [CrossRef] [PubMed]

13. Tucha, L.; Simpson, $\mathrm{W}$. The role of time on task performance in modifying the effects of gum chewing on attention. Appetite 2011, 56, 299-301. [CrossRef] [PubMed] 
14. Tucha, O.; Mecklinger, L.; Maier, K.; Hammerl, M.; Lange, K.W. Chewing gum differentially affects aspects of attention in healthy subjects. Appetite 2004, 42, 327-329. [CrossRef] [PubMed]

15. Onozuka, M.; Fujita, M.; Watanabe, K.; Hirano, Y.; Niwa, M.; Nishiyama, K.; Saito, S. Mapping brain region activity during chewing: A functional magnetic resonance imaging study. J. Dent. Res. 2002, 81, 743-746. [CrossRef] [PubMed]

16. Fang, M.; Li, J.; Lu, G.; Gong, X.; Yew, D.T. A fMRI study of age-related differential cortical patterns during cued motor movement. Brain Topogr. 2005, 17, 127-137. [CrossRef]

17. Miles, C.; Charig, R.; Eva, H. Chewing gum as context: Effects in long-term memory. J. Behav. Neurosci. Res. 2008, 6, 1-5.

18. Shiba, Y.; Nitta, E.; Hirono, C.; Sugita, M.; Iwasa, Y. Evaluation of mastication-induced change in sympatho-vagal balance through spectral analysis of heart rate variability. J. Oral Rehabil. 2002, 29, 956-960. [CrossRef]

19. Farella, M.; Bakke, M.; Michelotti, A.; Marotta, G.; Martina, R. Cardiovascular responses in humans to experimental chewing of gums of different consistencies. Arch. Oral Biol. 1999, 44, 835-842. [CrossRef]

20. Lexomboon, D.; Trulsson, M.; Wårdh, I.; Parker, M.G. Chewing Ability and Tooth Loss: Association with Cognitive Impairment in an Elderly Population Study. J. Am. Geriatr. Soc. 2012, 60, 1951-1956. [CrossRef]

21. Tucha, L.; Koerts, J. Gum chewing and cognition: An overview. Neurosci. Med. 2012, 3, 243-250. [CrossRef]

22. Plesh, O.; Bishop, B.; McCall, W. Effect of gum hardness on chewing pattern. Exp. Neurol. 1986, 92, 502-512. [CrossRef]

23. Moher, D.; Liberati, A.; Tetzlaff, J.; Altman, D.G. PRISMA Group Preferred reporting items for systematic reviews and meta-analyses: The PRISMA statement. BMJ 2009, 339, b2535. [CrossRef] [PubMed]

24. Higgins, J.P.T.; Altman, D.G.; Gøtzsche, P.C.; Jüni, P.; Moher, D.; Oxman, A.D.; Savović, J.; Schulz, K.F.; Weeks, L.; Sterne, J.A.C. The Cochrane Collaboration's tool for assessing risk of bias in randomised trials. BMJ 2011, 343, 1-9. [CrossRef] [PubMed]

25. Maher, C.G.; Sherrington, C.; Herbert, R.D.; Moseley, A.M.; Elkins, M. Reliability of the PEDro scale for rating quality of randomized controlled trials. Phys. Ther. 2003, 83, 713-721. [CrossRef]

26. Foley, N.C.; Teasell, R.W.; Bhogal, S.K.; Speechley, M.R. Stroke rehabilitation evidence-based review: Methodology. Top. Stroke Rehabil. 2003, 10, 1-7. [CrossRef] [PubMed]

27. Ryan, R.; Group, Cochrane Consumers and Communication Review Group. Cochrane Consumers and Communication Review Group: Data Synthesis and Analysis. June 2013. Available online: http://cccrg. cochrane.org (accessed on 6 April 2020).

28. Simons, D.; Kidd, E.A.M.; Brighton, D.; Jones, B. The effect of chlorhexidine/xylitol chewing-gum on cariogenic salivary microf lora: A clinical trial in elderly patients. Caries Res. 1997, 31, 91-96. [CrossRef] [PubMed]

29. Wennerholm, K.; Arends, J.; Birkhed, D.; Ruben, J.; Emilson, C.G.; Dijkman, A.G. Effect of xylitol and sorbitol in chewing-gums on mutans streptococci, plaque ph and mineral loss of enamel. Caries Res. 1987, 28, 48-54. [CrossRef]

30. Tzakis, M.G.; Carlsson, G.E.; Kiliaridis, S. Effect of chewing training on mandibular postural position. J. Oral Rehabil. 1989, 16, 503-508. [CrossRef]

31. Kiliaridis, S.; Tzakis, M.G.; Carlsson, G.E. Short-term and long-term effects of chewing training on occlusal perception of thickness. Eur. J. Oral Sci. 1990, 98, 159-166. [CrossRef]

32. Nakagawa, K.; Matsuo, K.; Takagi, D.; Morita, Y.; Ooka, T.; Hironaka, S.; Mukai, Y. Effects of gum chewing exercises on saliva secretion and occlusal force in community-dwelling elderly individuals: A pilot study. Geriatr. Gerontol. Int. 2017, 17, 48-53. [CrossRef] [PubMed]

33. Tzakis, M.G.; Karlsson, S.; Carlsson, G.E. Effects of intense chewing on some parameters of masticatory function. J. Prosthet. Dent. 1992, 67, 405-409. [CrossRef]

34. Tzakis, M.G.; Kiliaridis, S.; Carlsson, G.E. Effect of chewing training on masticatory efficiency. Acta Odontol. Scand. 1989, 47, 355-360. [CrossRef] [PubMed]

35. Tzakis, M.G.; Kiliaridis, S.; Carlsson, G.E. Effect of a fatigue test and chewing training on masticatory muscles. J. Oral Rehabil. 1994, 21, 33-45. [CrossRef]

36. Kiliaridis, S.; Tzakis, M.G.; Carlsson, G.E. Effects of fatigue and chewing training on maximal bite force and endurance. Am. J. Orthod. Dentofac. Orthop. 1995, 107, 372-378. [CrossRef] 
37. Masumoto, N.; Yamaguchi, K.; Fujimoto, S. Daily chewing gum exercise for stabilizing the vertical occlusion. J. Oral Rehabil. 2009, 36, 857-863. [CrossRef] [PubMed]

38. Takahashi, M.; Satoh, Y. Effects of gum chewing training on oral function in normal adults: Part 1 investigation of perioral muscle pressure. J. Dent. Sci. 2019, 14, 38-46. [CrossRef]

39. Kim, C.; Miquel, S.; Thuret, S. A 3-month mastication intervention improves recognition memory. Nutr. Health Aging 2019, 5, 33-42. [CrossRef]

40. Helkimo, M. Studies on function and dysfunction of the masticatory system. II. Index for anamnestic and clinical dysfunction and occlusal state. Sven. Tandlak. Tidskr. 1974, 67, 101-121.

41. Koc, D.; Dogan, A.; Bek, B. Bite Force and Influential Factors on Bite Force Measurements: A Literature Review. Eur. J. Dent. 2010, 04, 223-232. [CrossRef]

42. Brown, A.W.; Altman, D.G.; Baranowski, T.; Bland, J.M.; Dawson, J.A.; Dhurandhar, N.V.; Dowla, S.; Fontaine, K.R.; Gelman, A.; Heymsfield, S.B.; et al. Childhood obesity intervention studies: A narrative review and guide for investigators, authors, editors, reviewers, journalists, and readers to guard against exaggerated effectiveness claims. Obes. Rev. 2019, 20, 1523-1541. [CrossRef] [PubMed]

(C) 2020 by the authors. Licensee MDPI, Basel, Switzerland. This article is an open access article distributed under the terms and conditions of the Creative Commons Attribution (CC BY) license (http://creativecommons.org/licenses/by/4.0/). 